\title{
Hybrid Laparoscopic Versus Open Pancreatoduodenectomy. A Meta-Analysis
}

\author{
Miljana Vladimirov ${ }^{1} \cdot$ Dirk Bausch $^{2} \cdot$ Hubert J. Stein ${ }^{1} \cdot$ Tobias Keck $^{2} \cdot$ Ulrich Wellner $^{2}$
}

Accepted: 7 October 2021 / Published online: 18 January 2022

(C) The Author(s) 2022

\begin{abstract}
Introduction Hybrid laparoscopic techniques have been proposed as a good transition from open to complete minimally invasive approach especially in complex surgical procedures. This meta-analysis aimed to compare the outcomes of hybrid laparoscopic pancreatoduodenectomy versus open pancreatoduodenectomy.

Methods A systematic literature research was performed according to PRISMA guidelines. A broad search strategy with terms "laparoscopy" and "pancreatoduodenectomy" was used. Included studies were analyzed by quantitative meta-analysis using the metafor package for R software.

Results Of 655 identified articles, 627 were excluded and 28 articles fully assessed, including 14 comparative studies, 8 case series and 6 case reports. Extracted data included intraoperative variables and postoperative outcome parameters. The predefined inclusion criteria were met by 14 comparative studies, and 371 patients were pooled in the meta-analysis. Hybrid laparoscopic pacreatoduodenectomy was associated with significantly longer operative time $\left(I^{2} 0 \%, p=0,01\right.$, Mean HPD 494,6 min, Mean OPD 421,6 min, WMD $67 \mathrm{~min}$, 95\% CI 14-120 min). For all other postoperative outcome parameters, no statistically significant differences were found. A nonsignificant reduction in intraoperative transfusion rate $\left(I^{2} 20 \%, p=0,2\right.$, proportion HPD 2\%, proportion OPD 1,6\%, OR 0,44, 95\% CI 0,16-1,27) and blood loss $\left(I^{2} 95 \%, p=0,1\right.$, Mean HPD 397,2 ml, Mean OPD 1017,8 $\mathrm{ml}, \mathrm{MD}-601 \mathrm{ml}$, 95\% CI - 1311-108) was observed for hybrid pancreatoduodenectomy in comparison to open surgery.

Conclusions This meta-analysis demonstrates significantly increased operation time for hybrid laparoscopic compared to open pancreatoduodenectomy. Intraoperative variables as well as postoperative parameters and major morbidity were comparable for both techniques. Overall results of this meta-analysis demonstrated the hybrid technique as a safe procedure in high-volume centers offering aspects of a safe transition to fully laparoscopic pancreatoduodenectomy.
\end{abstract}

Tobias Keck

tobias.keck@ukhs.de

1 Klinik für Allgemein, Viszeral- und Thoraxchirurgie, PMU Nürnberg, Nuremberg, Deutschland

2 Klinik für Chirurgie, Universitätsklinikum SchleswigHolstein, Campus Lübeck, Ratzeburger Allee 160, 23538 Lübeck, Deutschland

\section{Introduction}

Currently, minimally invasive techniques are commonly used in gastrointestinal surgery and have also become increasingly popular in pancreatic surgery, even in pancreatoduodenectomy (PD), the most complex procedure.

In laparoscopic pancreatoduodenectomy, reconstruction is most challenging even for experienced surgeons, because pancreatojejunostomy or pancreatogastrostomy and hepaticojejunostomy have to be performed handsewn 
intracorporeally, whereas gastrojejunal anastomosis can be achieved laparoscopically by stapler. Laparoscopic pancreaticoduodenectomy is therefore associated with an increased rate of complications due to pancreatic fistula [1], and the learning curve for this complex procedure is yet to be defined [2].

Minimally invasive hybrid techniques as in two field esophagectomy, where a laparoscopic abdominal resection phase is combined with an open reconstruction via thoracotomy, have shown advantages in respect of pulmonary complications and global health owing to the reduced surgical trauma of laparoscopy [3] on the one hand and safe and easy implementation on the other hand.

Hybrid laparoscopic pancreatoduodenectomy is used to combine the advantages of laparoscopic pancreatoduodenal resection in combination with a well established open and safe reconstruction through a midline mini-laparotomy. Via this midline mini-laparotomy the specimen is removed, and the technically very demanding laparoscopic reconstruction is avoided [4].

The aim of this meta-analysis was to compare the results of hybrid laparoscopic pancreatoduodenectomy (HPD) versus open pancreatoduodenectomy (OPD) in comparative studies as well as to evaluate the results of hybrid laparoscopic pancreatoduodenectomy in published series.

\section{Methods}

\section{Operation}

Hybrid laparoscopic pancreatoduodenectomy is defined as a surgical technique in which the dissection phase is performed laparoscopically. The open reconstructions were performed via midline mini-laparotomies, varying in length between 4 and $10 \mathrm{~cm}$, in the same way as in open surgery. Different techniques of anastomoses (hepaticojejunostomy, pancreatogastrostomy or pancreatojejunostomy, duodenojejunostomy or gastrojejunostomy) were used, depending on the preference of the individual institution. The technique of hybrid laparoscopic pancreatoduodenectomy was performed as previously described [5, 6]. Open pancreatoduodenectomy was performed according to the preference of the institutions as pylorus-preserving pancreatoduodenectomy or subtotal stomach preserving pancreatoduodenectomy, and also here different anastomotic techniques were used. Neither type nor length of the incision was specified in the studies, with one exception, where a long upper midline incision or an inverted-L incision were described.

Indications for hybrid PD were benign as well as malignant pathologies of the pancreatic head (Supplemental Table 1). Selection criteria for hybrid laparoscopic
PD were defined by the operating institutions. Mainly patients with small lesions of the pancreatic head without perivascular invasion and who did not have previous extensive upper abdominal surgery were referred for hybrid laparoscopic PD.

\section{Literature search}

A systematic literature research was performed according to PRISMA guidelines [7] in the PubMed database for studies published until March 1, 2021. Search terms used were "laparoscopy" (approach) and "pancreatoduodenectomy" (procedure). Titles, abstracts and text of the articles were screened based on inclusion and exclusion criteria. Only studies comparing hybrid pancreatoduodenectomy with open pancreatoduodenectomy, case series and case reports, were included. If repeatedly published series were found, only the most recent study was considered. Also articles after manual search in reference lists of related meta-analyses [8-11] and systematic review articles were included. Articles in other languages than English, duplicate articles, not relevant articles, studies on animals were excluded. Comparative studies were only included if at least one outcome variable of interest was reported.

\section{Assessment of quality of studies}

Only non-randomized studies were detected. The quality of the studies was appraised according to Cochrane guidelines, and the risk of bias has been classified in high, unclear, or low risk of bias [12]. Additionally, all comparative studies were assessed according to the Maastricht-Amsterdam criteria. Included studies were ranked with a maximum of 19 points. Studies with a score less than 9 were considered of low quality.

\section{Data extraction}

Extracted outcome data of interest in this meta-analysis included operative outcomes (operative time, intraoperative blood loss, intraoperative transfusion, conversion to open approach) and postoperative outcomes (mortality, pancreatic fistula B/C [13], postpancreatectomy hemorrhage [14], delayed gastric emptying [15], hepaticoenterostomy leakage, overall complications, reoperation, morbidity classified according Clavien-Dindo Grade 2 to 5 [16], surgical site infections, length of hospital stay).

\section{Statistical analysis}

Meta-analysis for comparative studies was performed according to recommendations of Cochrane guidelines and 
statistically processed by the metafor package [17] for $R$ software.

Categorical data were presented as frequencies and percentages. Continuous data were presented as stated in included original articles.

Mean and standard deviation were extracted from a study when available. $I^{2}$ was used to quantify heterogeneity between studies (Tables 1 and 2) [18]. For low and moderate heterogeneity $\left(I^{2}<50 \%\right)$, the fixed effect model was used. In case of considerable heterogeneity $\left(I^{2}>50 \%\right)$, the random effect model was used. In forest plots, estimates were expressed as weighted mean difference for continuous data and odds ratio for event related outcomes and were all reported with corresponding $95 \%$ confidence intervals (CI).

Sensitivity analysis was performed excluding studies of low quality: only studies with at least nine points according to the Amsterdam criteria were included.

\section{Results}

The PRISMA flow diagram is shown in Fig. 1. In total, 655 articles were identified. After screening titles and abstracts 180 articles remained. After evaluation of the full text of these articles and reference lists of meta-analyses and reviews another 152 articles were excluded. Fourteen comparative studies, eight case series, and six case reports with a total of 505 patients were included in the study. Fourteen comparative studies with 371 patients were suitable for meta-analysis.

Table 1 Heterogeneity analysis of all included studies

\begin{tabular}{lll}
\hline Parameter & $I^{2}$ value & $p$ value, $I^{2}$ test \\
\hline Mortality & 0 & 0,998 \\
DGE & 61,509 & 0,001 \\
POPF B/C & 34,07 & 0,14 \\
PPH & 0 & 0,857 \\
Transfusion & 50,999 & 0,005 \\
Hepatic leak & 0 & 0,855 \\
Reoperation & 0 & 0,861 \\
SSI & 89,022 & 0 \\
Clavien-Dindo & 38,697 & 0,081 \\
Operative time & 99,13 & 0 \\
Complications & 88,297 & 0 \\
Conversion & 93,764 & 0 \\
Blood loss & 93,543 & 0 \\
OHS & 0 & 0,682
\end{tabular}

$I^{2}$ value heterogeneity measure; $p$ value of $I^{2}$ test $(p<0,05$ significant)
Table 2 Heterogeneity analysis of comparative studies

\begin{tabular}{lllll}
\hline Parameter & $\mathrm{I}^{2}$ value & $p$ value, $I^{2}$ test & OR.FE.p & OR.RE.p \\
\hline Mortality & 0 & 0,864 & 0,961 & 0,961 \\
DGE & 14,358 & 0,323 & 0,415 & 0,553 \\
POPF B/C & 32,181 & 0,182 & 0,261 & 0,415 \\
PPH & 0 & 0,963 & 0,397 & 0,397 \\
Transfusion & 20,348 & 0,28 & 0,211 & 0,211 \\
Hepatic leak & 1,453 & 0,362 & 0,891 & 0,891 \\
Reoperation & 0 & 0,914 & 0,563 & 0,563 \\
SSI & 0,779 & 0,388 & 0,019 & 0,019 \\
Clavien-Dindo & 0 & 0,503 & 0,248 & 0,248 \\
Operative time & 0 & 0,379 & 0,013 & 0,013 \\
Complications & 64,555 & 0,037 & 0,001 & 0,096 \\
Conversion & 0 & 0,621 & 0 & 0 \\
Blood loss & 94,881 & 0 & 0 & 0,097 \\
OHS & 0 & 1 & 0,429 & 0,429 \\
\hline
\end{tabular}

$I^{2}$ value heterogeneity measure; $p$ value of $I^{2}$ test $(p<0,05$ significance); OR.FE.p pvalue in Fixed Effect Model; OR.RE. p $p$ value in Random Effect Model

Descriptive meta-analysis was performed including all available cases of hybrid-laparoscopic pancreatoduodenectomy, also from non-comparative series and reports. Given the relative paucity of comparative data, this enabled to include a larger number of patients.

Characteristics of included studies are shown in Table 3. Quality of studies is shown detailed in supplementary material as Supplemental Tables 2 and 3. Results of heterogeneity for all studies are shown in Tables 1 and 2 . Operative and postoperative outcomes for all hybrid pancreatoduodenectomies as well as for comparative studies are shown in the forest plots (Figs. 2, 3, 4, 5, 6, 7, 8, 9, 10, 11,12 as well as in supplementary materials Suplemental Figures 1-16).

Most studies were designed as feasibility studies, and long-term outcome was not reported.

The largest matched-pair analysis comparing hybrid PD versus OPD assessing long-term overall survival and oncologic outcome which was presented, found a trend of improved overall survival in patients receiving hybrid PD [42]. Radical oncologic resection could also be performed safely by hybrid PD in cancer patients.

\section{Operative outcomes}

The average operative time estimated for all included hybrid laparoscopic PD was 420 min (95 \% CI 319-520). Operative time was significantly longer for hybrid laparoscopic PD compared to open PD (Mean HPD 494,6 min, Mean OPD 421,6 min, mean difference $67 \mathrm{~min}, 95 \% \mathrm{CI}$ 
Fig. 1 The PRISMA

flowchart of literature review

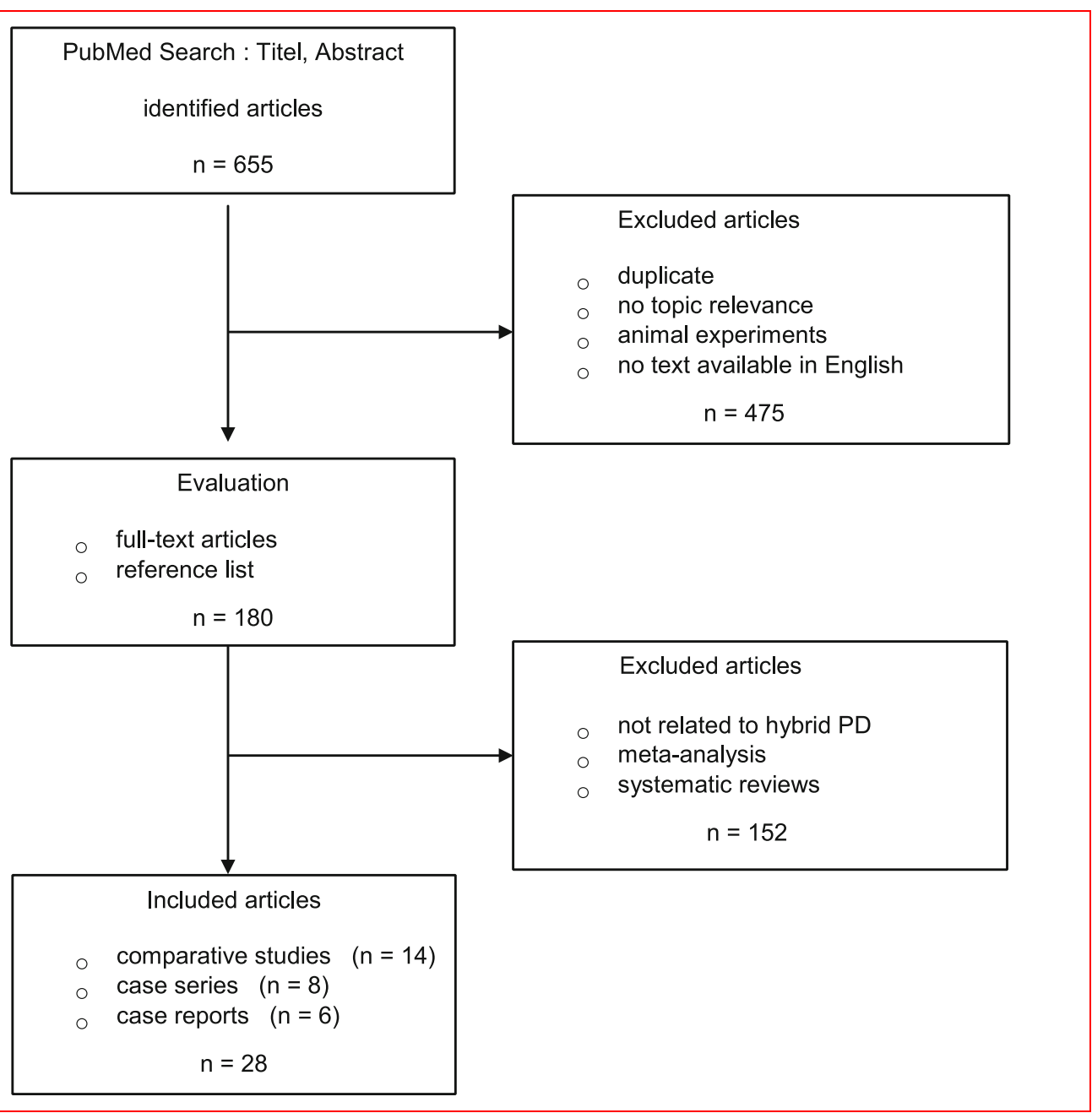

The rates of pancreatic fistula, postpancreatectomy hemorrhage, delayed gastric emptying, morbidity (Clavien-Dindo 2-5), overall complications, mortality, and surgical site infection were lower for hybrid laparoscopic PD, but did not differ significantly to open PD (Fig. 10, Supplemental Figures 2, 9, 10, 8, Fig. 12, Supplemental Figure 3).

For all hybrid laparoscopic PD, the rate of hepaticoenterostomy leakage was $3 \%$ (Supplemental Figure 11) and the rate for reoperation was $7 \%$ (Supplemental Figure 15). Both rates were higher in hybrid PD, but also differed not significantly from open PD in comparative studies (Supplemental Figures 12 and 16).

Mean overall hospital stay for all hybrid PD was 16,68 days (Supplemental Figure 13). The only evaluable comparative study showed, that overall hospital stay was longer in the hybrid PD group without statistically significance (Supplemental Figure 14). 
Table 3 Overview of all hybrid pancreatoduodenectomies (study characteristics)

\begin{tabular}{|c|c|c|c|c|c|c|c|c|c|}
\hline \multirow[t]{2}{*}{ Author, Year } & \multirow[t]{2}{*}{$n$} & \multirow[t]{2}{*}{ Type of article } & \multicolumn{2}{|c|}{ Resection } & \multicolumn{5}{|c|}{ Reconstruction } \\
\hline & & & Lap & HA & PG & PJ & $\mathrm{HJ}$ & GJ & DJ \\
\hline Gagner [19], 1994 & 1 & FB & + & & & Lap & Lap & & $\mathrm{o}$ \\
\hline Cuschieri [20], 1994 & 2 & FB & + & & $?$ & $?$ & $?$ & $?$ & $?$ \\
\hline Ammori [21], 2004 & 1 & FB & & + & $\mathrm{O} ?$ & $\mathrm{O} ?$ & o & $\mathrm{O} ?$ & $\mathrm{O} ?$ \\
\hline Kimura [22], 2005 & 1 & FB & & + & & $\mathrm{o} / \mathrm{HA}$ & $\mathrm{o} / \mathrm{HA}$ & & o \\
\hline Staudacher [23], 2005 & 4 & $\mathrm{~S}$ & + & & & o & o & & o \\
\hline Mabrut [24], 2005 & 3 & $\mathrm{~S}$ & +2 & +1 & $\mathrm{O} ?$ & $\mathrm{O} ?$ & o & $\mathrm{O} ?$ & $\mathrm{O} ?$ \\
\hline Dulucq [25], 2006 & 9 & KS(TL/LA) & + & & & o & o & o & \\
\hline Pugliese [26], 2008 & 7 & KS(TL/LA) & + & & & o & o & o & o \\
\hline Cho [27], 2009 & 15 & $\mathrm{KS}$ & + & & & o & o & & o \\
\hline Suzuki [28], 2012 & 6 & $\mathrm{~S}$ & & + & o 3 & o 3 & o & o & \\
\hline Asbun [29], 2012 & 3 & $\mathrm{KS}$ & & + & HA? & HA? & HA? & HA? & HA? \\
\hline Kuroki [30], 2012 & 20 & $\mathrm{KS}$ & + & & & o & o & o & o \\
\hline Nakamura [31], 2012 & 12 & $\mathrm{~S}$ & + & & & HA & Lap & & HA? \\
\hline Lee [32], 2013 & 42 & $\mathrm{~S}$ & + & & o & & Lap & & o \\
\hline Langan [33], 2014 & 28 & $\mathrm{KS}$ & & + & $\mathrm{O} ?$ & $\mathrm{O} ?$ & o & & o \\
\hline Speicher [34], 2014 & $31 ?$ & KS(TL/LA) & + & & $\mathrm{O} ?$ & $\mathrm{O} ?$ & o & $\mathrm{O} ?$ & $\mathrm{O} ?$ \\
\hline Wang [35], 2014 & 13 & $\mathrm{KS}$ & + & & & o & o & o & \\
\hline Dokmak [1], 2015 & 46 & $\mathrm{KS}$ & + & & & Lap & Lap & $\begin{array}{c}\text { Lap/ } \\
\text { o }\end{array}$ & \\
\hline Liu [36], 2015 & 21 & $\mathrm{~S}$ & + & & o & & Lap & & o \\
\hline Mendoza [37], 2015 & 18 & $\mathrm{KS}$ & + & & & o & o & o 2 & o 16 \\
\hline Zimmitti [38], 2016 & 1 & FB & + & & o & & Lap & o & \\
\hline Koh [39], 2016 & 1 & FB & + & & & $\mathrm{O}$ & o & o & \\
\hline Patel [40], 2017 & 17 & KS(TL/LA) & + & & & $\mathrm{O}$ & o & o & \\
\hline Hilst [41], 2018 & 56 & KS(TL/LA) & + & & & $\mathrm{O}$ & o & $\mathrm{O} ?$ & $\mathrm{O} ?$ \\
\hline $\begin{array}{l}\text { Deichmann [42], } \\
2018\end{array}$ & 60 & KS & + & & o & & o & & o \\
\hline Pham [43], 2020 & 18 & $\mathrm{~S}$ & + & & & $\mathrm{O}$ & o & o & \\
\hline Wang [44], 2020 & 48 & KS(TL/LA) & + & & & $\mathrm{O}$ & o & o & \\
\hline Al-Sadairi [45], 2021 & 21 & $\mathrm{~S}$ & + & & & $\mathrm{O}$ & o & o & \\
\hline
\end{tabular}

Particularities: Kimura additionally Braun Anastomosis, Liu additionally Braun Anastomosis open

FB case report; S case series; KS comparative study; Lap laparoscopic; HA handassisted; TL total laparoscopic; LA laparoscopic assisted; o open; PG Pancreatogastrostomy; PJ Pancreatojejunostomy; HJ Hepaticojejunostomy; DJ Duodenojejunostomy; GJ Gastrojejunostomy

$\mathrm{O}$ ? case number of open performed reconstruction not spicified; ? not specified; $\mathrm{n}$ case number

\section{Discussion}

Laparoscopic gastrointestinal surgery has been demonstrated to result in reduced postoperative pain, shorter hospital stay, rapid return to baseline performance status, and reduced morbidity with oncological equivalency, when compared to the traditional open procedure. Laparoscopic procedures, therefore, have rapidly gained widespread acceptance [46].

The use of minimally invasive pancreatoduodenectomy (MIPD) has increased but is still performed by a limited number of institutions and is lagging compared with the implementation of laparoscopic distal pancreratectomy.

Laparoscopic pancreatoduodenectomy is very challenging even for experienced pancreatic surgeons because three difficult laparoscopic anastomoses must be performed with potentially life-threatening complications [47].

The learning curve for this complex procedure is not yet defined [2]. In centers performing less than 10 MIPDs annually, this technique was associated with higher perioperative mortality compared with open pancreatoduodenectomy $[40,41]$. Publications of series of more than 20 
Fig. 2 Forest plot; average operative time of all HPD's in minutes operative time

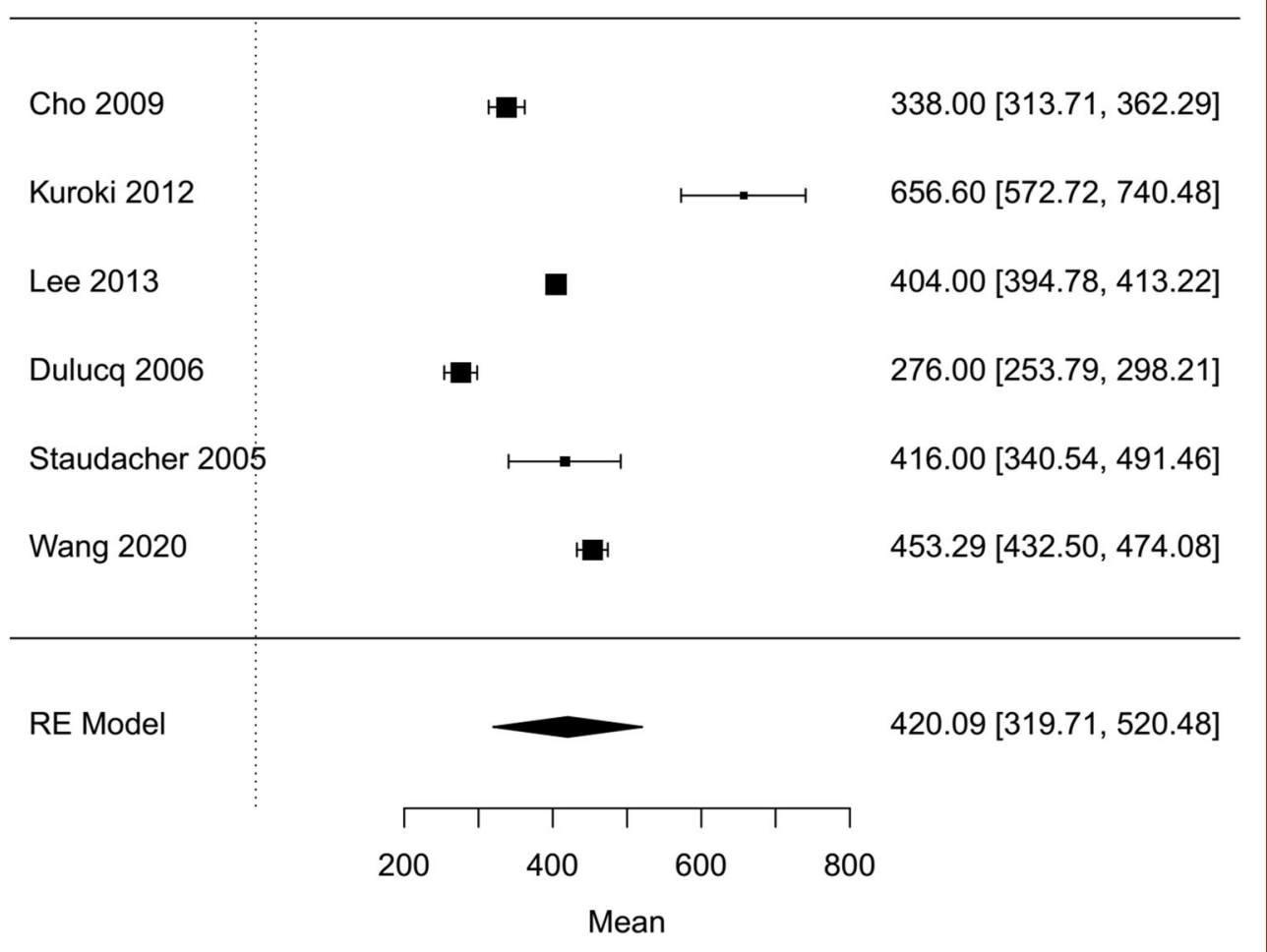

Fig. 3 Forest plot; mean difference of operative time in comparative studies (comparison between HPD and OPD) operative time

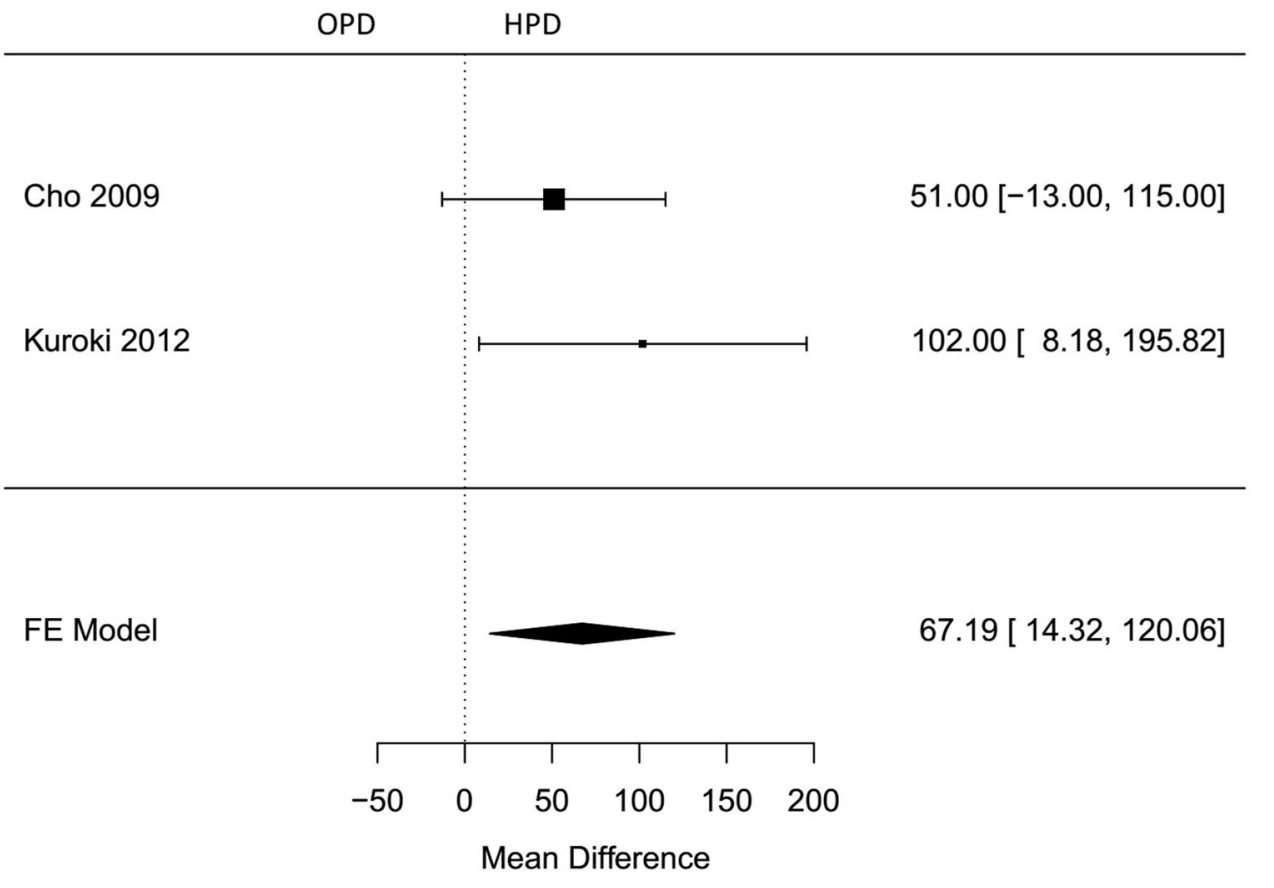

cases demonstrate a decrease in the average operative time, showing that pancreatic surgeons with minimally invasive expertise may be able to perform MIPD with similar operative times as open procedures [48]. A retrospective multicenter propensity matched cohort study comparing MIPD cases to OPD controls from European centers, 
Fig. 4 Forest plot; transfusion rate of all HPD's transfusion

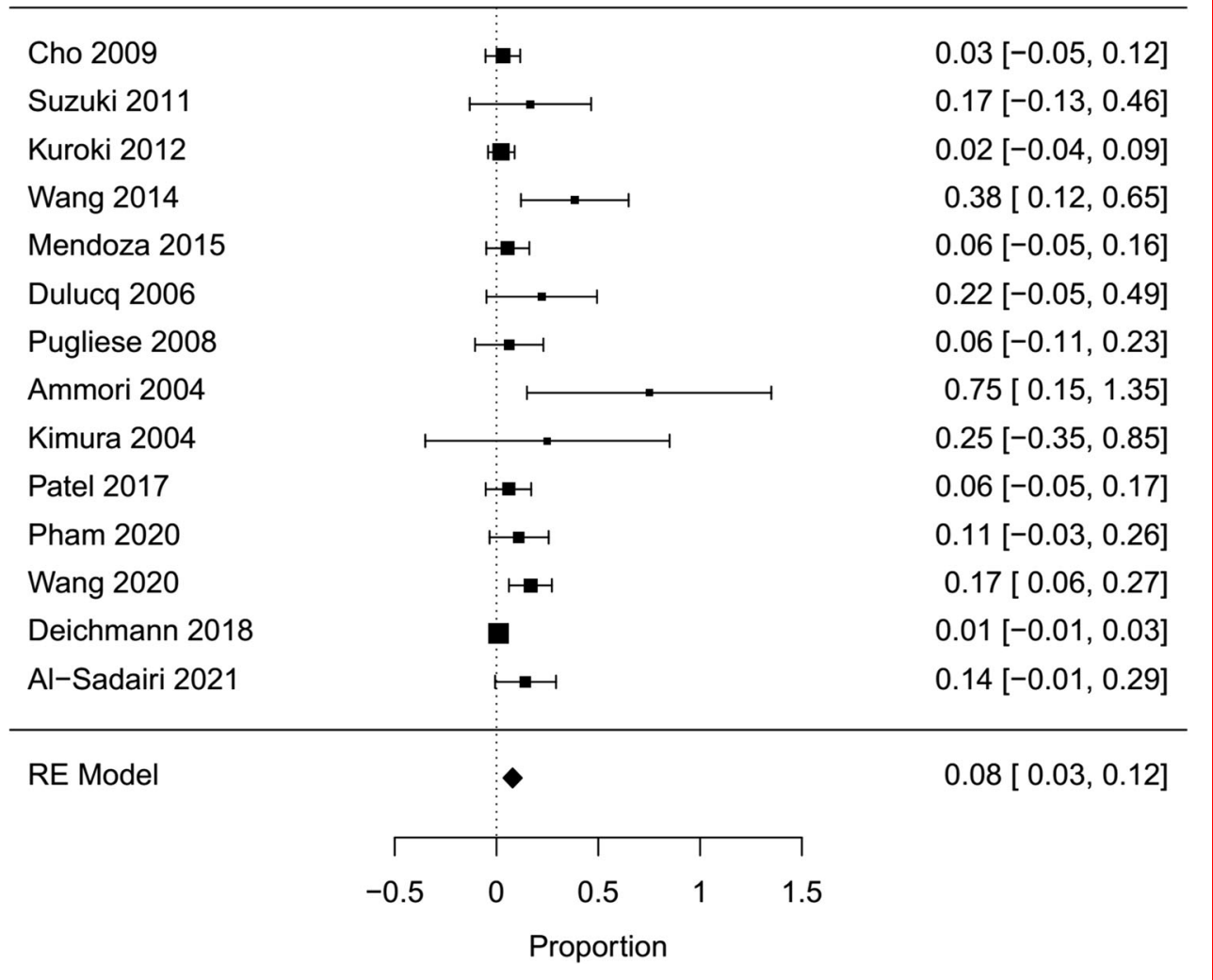

Fig. 5 Forest plot; transfusion rate in comparative studies (comparison between HPD and OPD)

\section{transfusion}

OPD

HPD

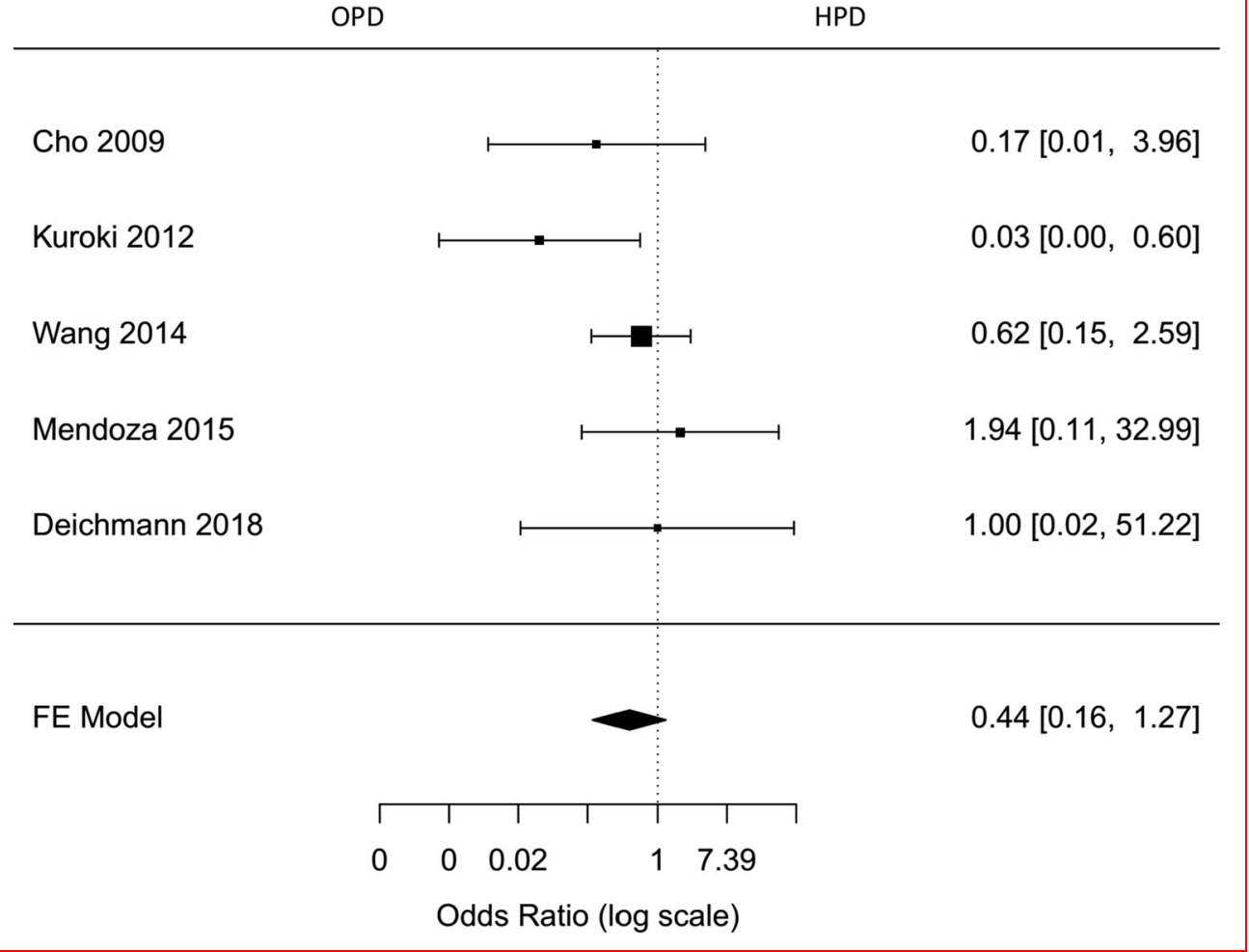


Fig. 6 Forest plot; average intraoperative blood loss of all HPD's in milliliter

\section{blood loss}

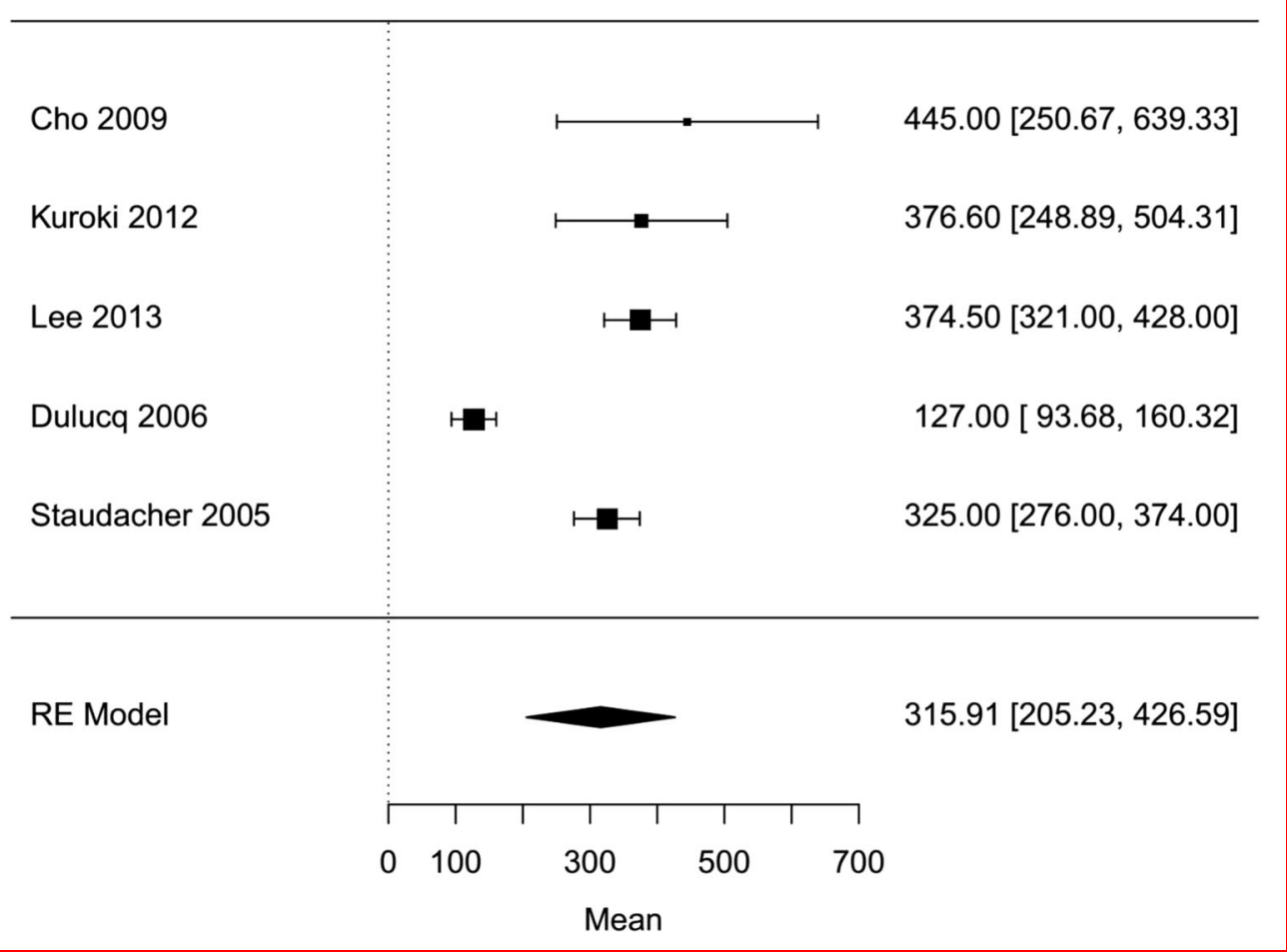

Fig. 7 Forest plot; mean difference in intraoperative blood loss between HPD and OPD in milliliter blood loss

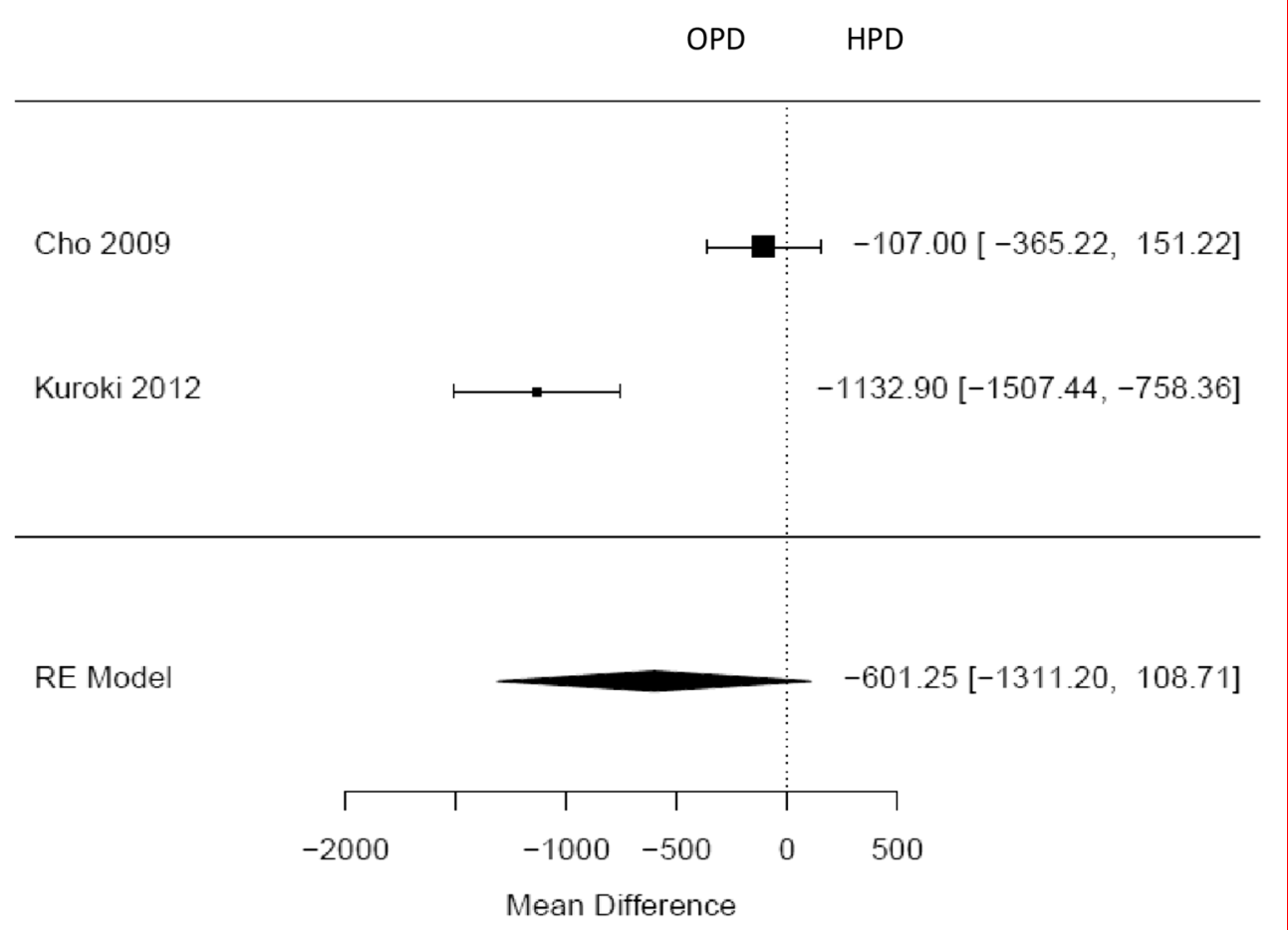


Fig. 8 Forest plot; conversion rate of all HPD's conversion

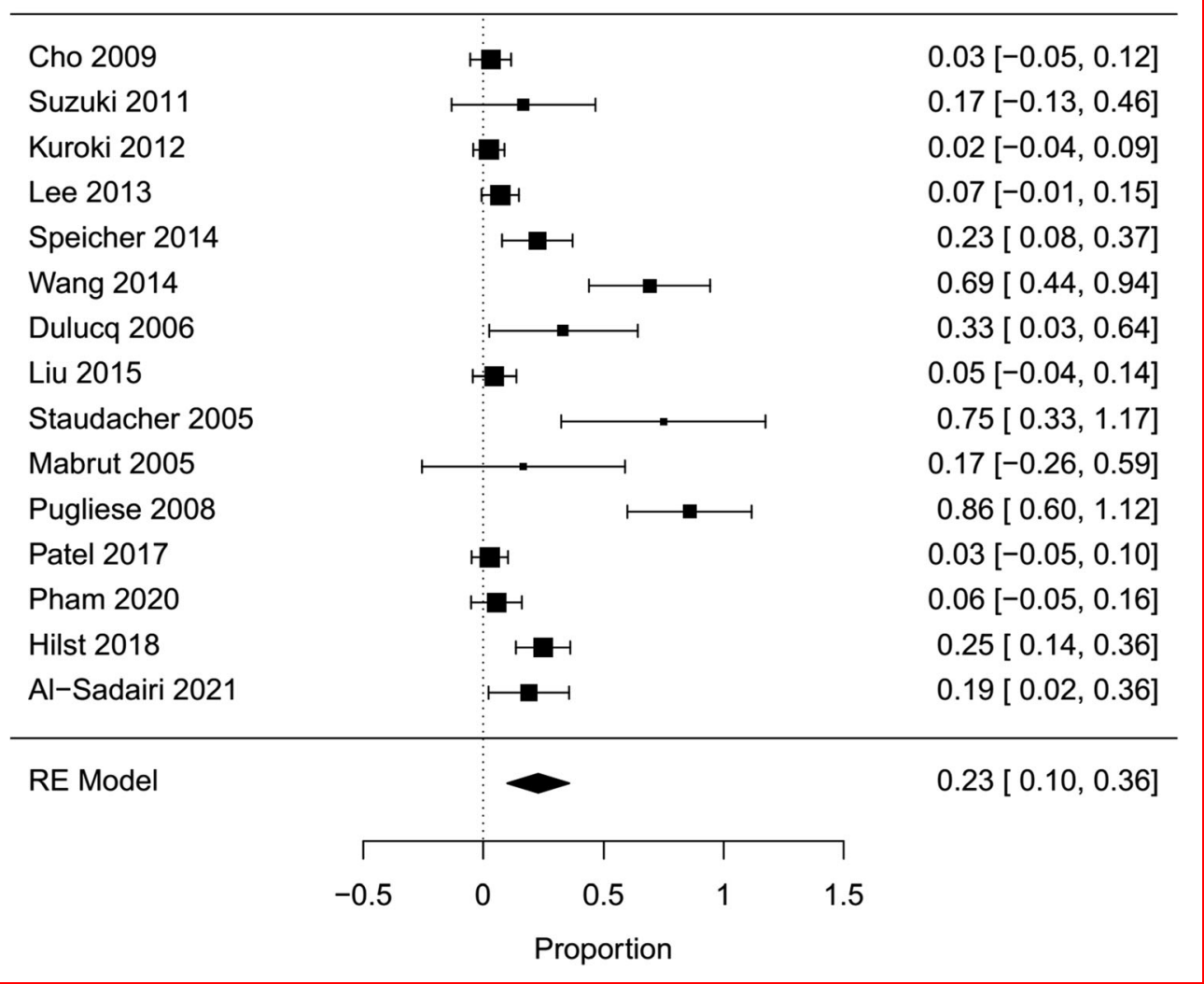

performing at least 10 MIPDs per year, found no differences in major morbidity, mortality and length of stay between MIPD and OPD. MIPD was, however, associated with a $10 \%$ higher rate of grade B/C POPF and longer operative times.

In a previous analysis there were no differences in outcomes between laparoscopic-assisted, robot-assisted-, and hybrid-PD (major morbidity: $27 \%$ vs. $27 \%$ vs. $35 \%$; POPF: $24 \%$ vs. $19 \%$ vs. $25 \%$; 30-day mortality: $2,9 \%$ vs. $5,2 \%$ vs. 5,4\%). Single-row pancreatojejunostomy was identified as a risk factor for POPF in MIPD [47]. One published randomized trial on laparoscopic versus OPD for periampullary tumors was underpowered to demonstrate the benefit regarding major morbidity [49]. Improved outcomes in centers performing more than 40 OPDs annually could indicate that the optimal minimum quantity for MIPD is also higher [47].

A cutoff of 20 MIPD was recommended in an international survey among 435 pancreatic surgeons [50], and a minimum of 20 totally MIPD was also decided to be the cutoff to participate in the LEOPARD-2 trial [51]. This first randomized controlled multicenter study was designed to assess whether MIPD reduces time to functional recovery as compared with OPD. The study protocol allowed laparoscopic surgery and robot-assisted surgery because both were considered equivalent methods of MIPD [52]. The LEOPARD-2 trial was prematurely terminated because laparoscopic pancreatoduodenectomy was associated with more complication-related deaths than open pancreatoduodenectomy [51]. Experience, learning curve, and volume influenced the outcome.

All of these studies well demonstrate that even in wellestablished training settings the learning curve is flat and a high number of cases are needed to implement safe and reproducible results.

To improve the results of MIPD and disseminate MIPD, application of dedicated programs might be useful as has been previously shown in the Netherlands for laparoscopic distal pancreatectomy (LAELAPS) [53]. A volume-outcome relation seems to be stronger for laparoscopic pancreatoduodenectomy, so that the LEOPARD-2 trial participating centers were required to take part in a training programme (LAELAPS-2) and performed a median of 19 (range 15-23) laparoscopic pancreatoduodenectomies annually [54]. During the trial, the randomization decreased this annual volume per participating center to a median of 11 (range 6-15) procedures. Therefore a negative influence of this reduction in center volume cannot be ruled out [51]. 
Fig. 9 Forest plot; pancreatic fistula B/C rate of all HPD's
POPF B/C

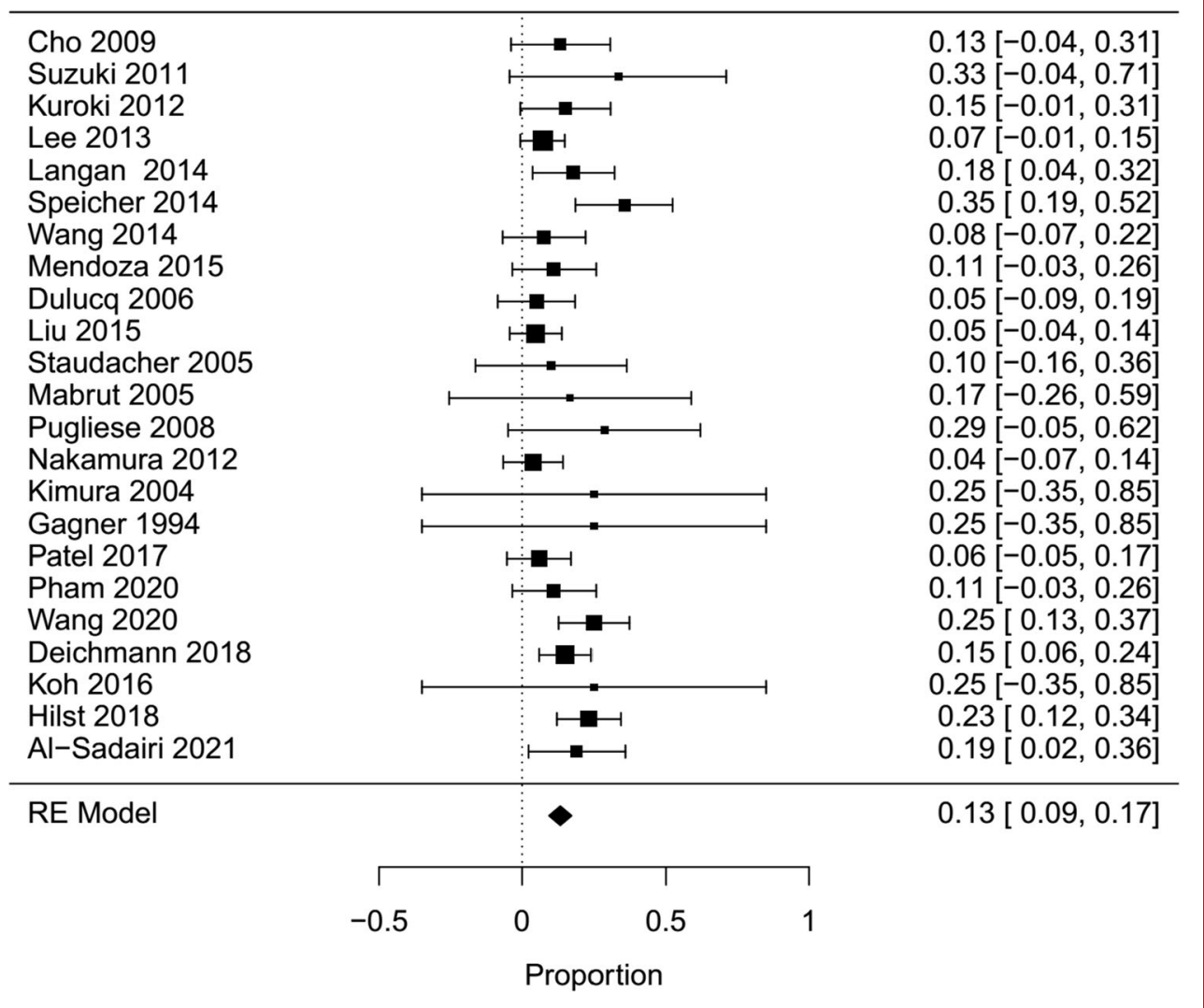

In addition, hybrid laparoscopic pancreatoduodenectomy is used in the implementation phase of minimally invasive $\mathrm{PD}$ to combine the potential advantages of laparoscopic pancreatoduodenal resection with well-established open and safe reconstruction. The hybrid approach aims to avoid the technically demanding laparoscopic anastomoses. Because there are no prospective randomized controlled studies comparing the open approach to the hybrid laparoscopic technique, this meta-analysis was performed as the best means to gather more evidence.

The presented systematic review of the literature revealed 14 comparative studies: eight case series and six case reports. The definition of a high-volume center of pancreatic surgery varies widely and various cutoffs for defining high-volume centers are used. The best model of high-volume centers was an annual institution resection volume of 19 or more. Based on the information provided within the included comparative studies, all institutions crossed a cutoff of 20 pancreatic resections annually. So all institutions met the criterion of a high volume center. Due to the application of metafor package in $\mathrm{R}$ [17] for statistical analysis, the detected studies could be included in the meta-analysis. Therefore, included studies are heterogeneous and selection bias was a common problem.
According to Cochrane guidelines and Maastrich-Amsterdam criteria, the included studies were rated with moderate quality.

For comparison of operative time, only two studies specifying mean operative time were available. These studies showed a significantly longer operative time for hybrid laparoscopic pancreatoduodenectomy. Due to the complexity of the intervention, this took approximately $1 \mathrm{~h}$ longer than the open procedure. As mentioned above, unlike many other laparoscopic procedures, laparoscopic pancreatoduodenectomy seems to require a very long learning period [34]. The largest matched-pair analysis comparing hybrid versus open pancreatoduodenectomy was the first demonstrating a significantly shorter median operative time for the hybrid pancreatoduodenectomy 352 min versus 397 min for open pancreatoduodenectomy [42]. This is supported by the lowest mortality rate in studies with higher case numbers [30, 32, 42]. The calculated mortality rate in this meta-analysis was not statisticaly significant higher for open approach with Odds ratio of 0,62 (proportion HPD 2\%, proportion OPD 2\%, $95 \% \mathrm{CI}$ 0,16-2,41). According to data of the National Cancer Database of the USA, mortality of laparoscopic pancreatoduodenectomy was $4,8 \%$ compared to $3,7 \%$ after open 
Fig. 10 Forest plot; pancreatic fistula $\mathrm{B} / \mathrm{C}$ rate in comparative studies (comparison between HPD and OPD)
POPF B/C

OPD

HPD

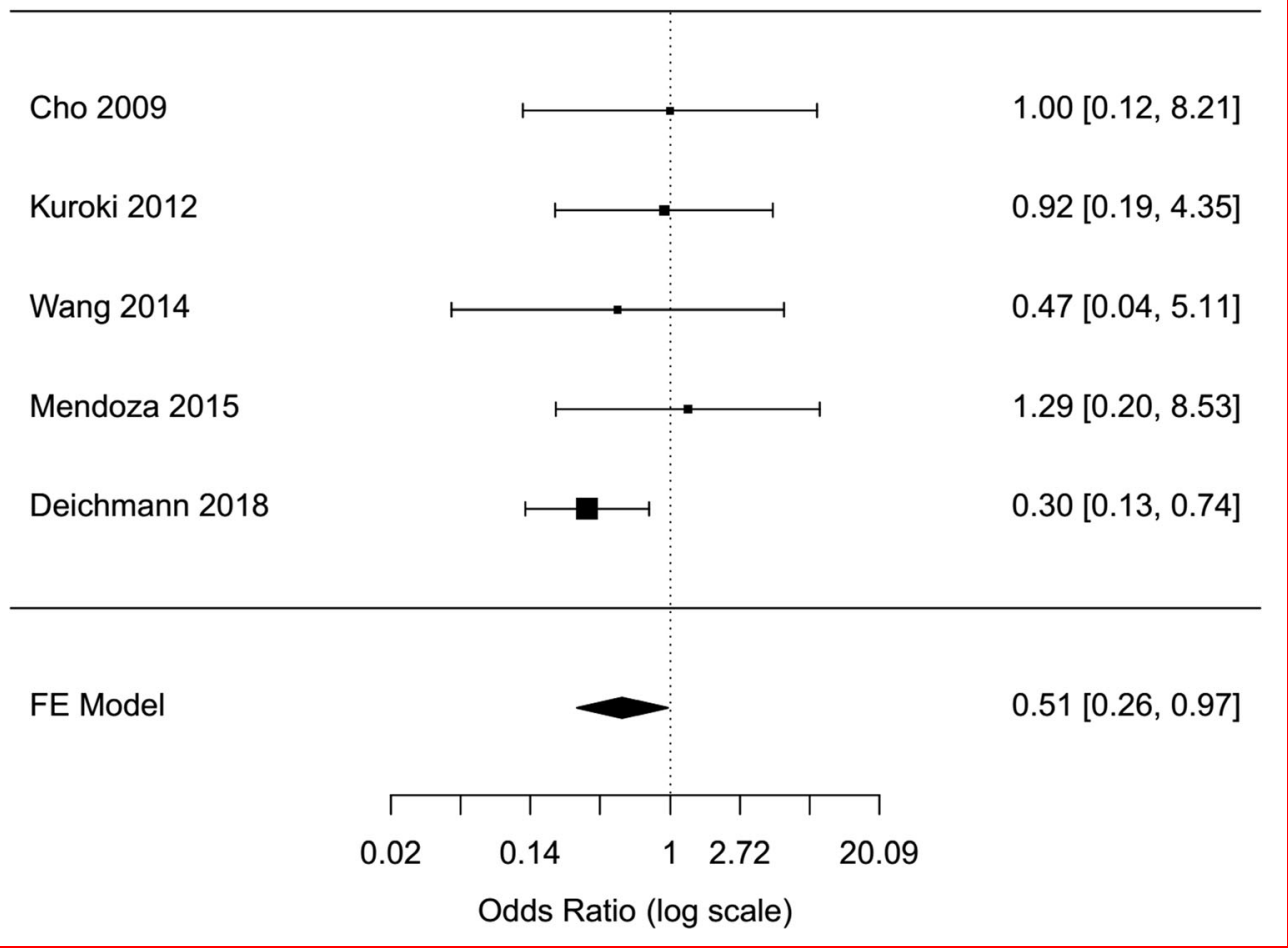

pancreatoduodenectomy [55]. The higher mortality rate occurred in hospitals with less than 10 laparoscopic pancreatic resections per year [56], again underlining the complex learning curve of this procedure.

Hybrid laparoscopic pancreatoduodenectomy showed lower transfusion rate and blood loss, which were not statistically significant. This can be explained by magnification of the visible field of laparoscopy and has been shown for other laparoscopic approaches in similar fashion.

In this meta-analysis, the estimated overall conversion rate from hybrid laparoscopic to open pancreatoduodenectomy was still high with $23 \%$ and may be interpreted in part as a result of patient selection. Frequently, pancreatic adhesions to the mesentericoportal vein resulted in preemptive conversion to the open approach [57]; however, the decisions for conversion were not mentioned in every study reported.

Postoperative outcomes were comparable for both techniques. In meta-analysis of comparative studies, the insufficiency rate of pancreatic anastomosis-a potentially life-threatening complication-was lower but not significantly lower after minimally invasive pancreatoduodenectomy (proportion HPD $16 \%$, proportion OPD $20 \%$, Odds ratio $0,51,95 \% \mathrm{CI} 0,26-0,97)$. The leakage rate for hepaticoenterostomy after the hybrid approach was higher, but again not statistically significant (proportion HPD $2 \%$, proportion OPD $2 \%$, Odds ratio 1,14, $95 \%$ CI 0,18-7,07). This is not unexpected, because in both operative techniques open pancreatogastrostomy or pancreatojejunostomy were performed. Estimated risk of pancreatic fistula in all analyzed articles differed between 4 and $35 \%$ [31, 34]. Possible reasons may be different anastomotic techniques. An insufficiency of the pancreatic anastomosis with following abscess or bleeding are the main reasons for reoperations. Results of this meta-analysis showed for all hybrid laparoscopic pancreatoduodenectomy a reoperation rate of $7 \%$. In comparative studies, reoperation rate after laparoscopic and open pancreatoduodenectomy were comparable for both groups (proportion HPD $4 \%$, proportion OPD $4 \%$, Odds ratio 1,24, $95 \%$ CI 0,07-20,57). Postpancreatectomy hemorrhage was lower after a hybrid approach without statistical significance (proportion HPD 4 $\%$, proportion OPD $5 \%$, Odds ratio $0,64,95 \%$ CI 0,23-1,80). Clinically relevant delayed gastric emptying occurred less frequently in hybrid pancreatoduodenectomy, but it varied not significantly different from open approach (proportion HPD $7 \%$, proportion OPD $8 \%$, Odds ratio 0,71, $95 \%$ CI 0,31-1,63).

Despite a smaller incision used for mini-laparotomy in hybrid technique, surgical site infection rate was not 


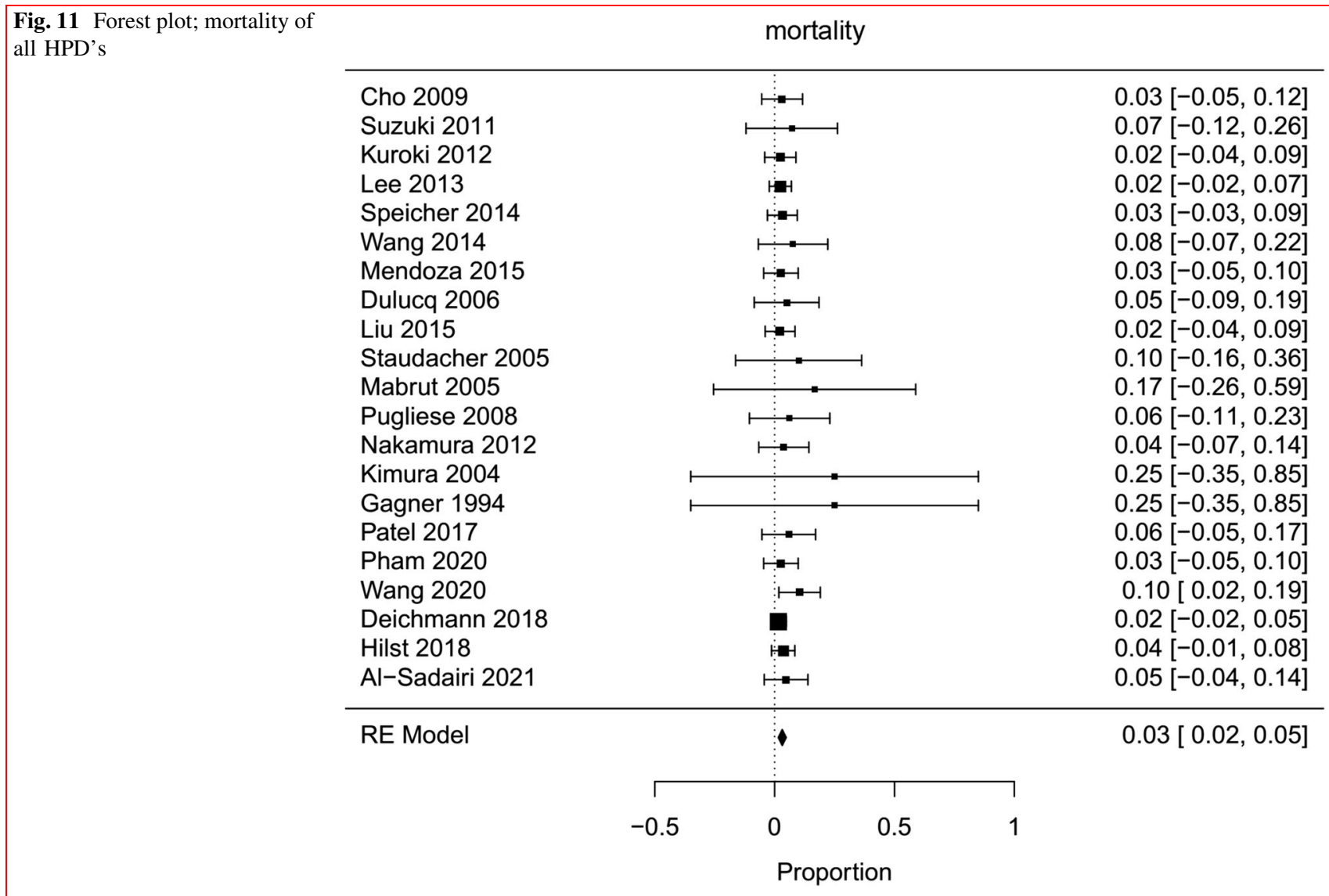

significantly higher in the open technique (proportion HPD $19 \%$, proportion $13 \%$, Odds ratio $0,67,95 \%$ CI 0,11-3,97).

A statistical analysis of length of hospital stay was possible only in one comparative study. Mean hospital stay was $16,4 \pm 3,7$ days for hybrid pancreatoduodenectomy and 15,6 $\pm 1,3$ days for the open approach. The difference of 0,8 days was not statistically significant. The authors postulate that there will be advantages for the duration of hospital stay for laparoscopy with increasing experience [27].

Although this meta-analysis showed no benefit of hybrid pancreatoduodenectomy, the open reconstruction may provide an alternative for, or a step-up technique to laparoscopic/robot-assisted surgery during the learning curve, because there was no disadvantage concerning safety of the reconstruction even in the reported series that might represent the learning curve of several centers [58]. The next step should be a comparison of laparoscopic versus robotic PD. Although the frequency of robotic operations increases, it is not feasiable at the moment, because comparative studies are lacking. Experience and operative frequency influenced the outcome and improved the results of MIPD. The largest mached pair analyses comparing hybrid pancreatoduodenectomy with open pancreatoduodenectomy in 120 patients showed a reduction in clinically relevant postoperative complications, faster recovery for the hybrid technique and an equal longterm onologic outcome [42]. Therefore, a hybrid pancreatoduodenectomy can be considered as a save transitional procedure to total laparoscopic or robot-assisted pancreatoduodenectomy. This further development should be investigated in a prospective study. Their implantation is likely to be difficult, as the data of the interrupted LEOPARD-2 Study showed.

\section{Conclusions}

Data determined in this meta-analysis advised the implementation of hybrid pancreatoduodenectomy, although this study has restrictions due to missing prospective studies. This meta-analysis demonstrates significantly increased operation time for hybrid laparoscopic pancreatoduodenectomy, while major morbidity remains comparable to open technique. Overall results of this meta-analysis 
Fig. 12 Forest plot; mortality rate in comparative studies (comparison between HPD and OPD) mortality

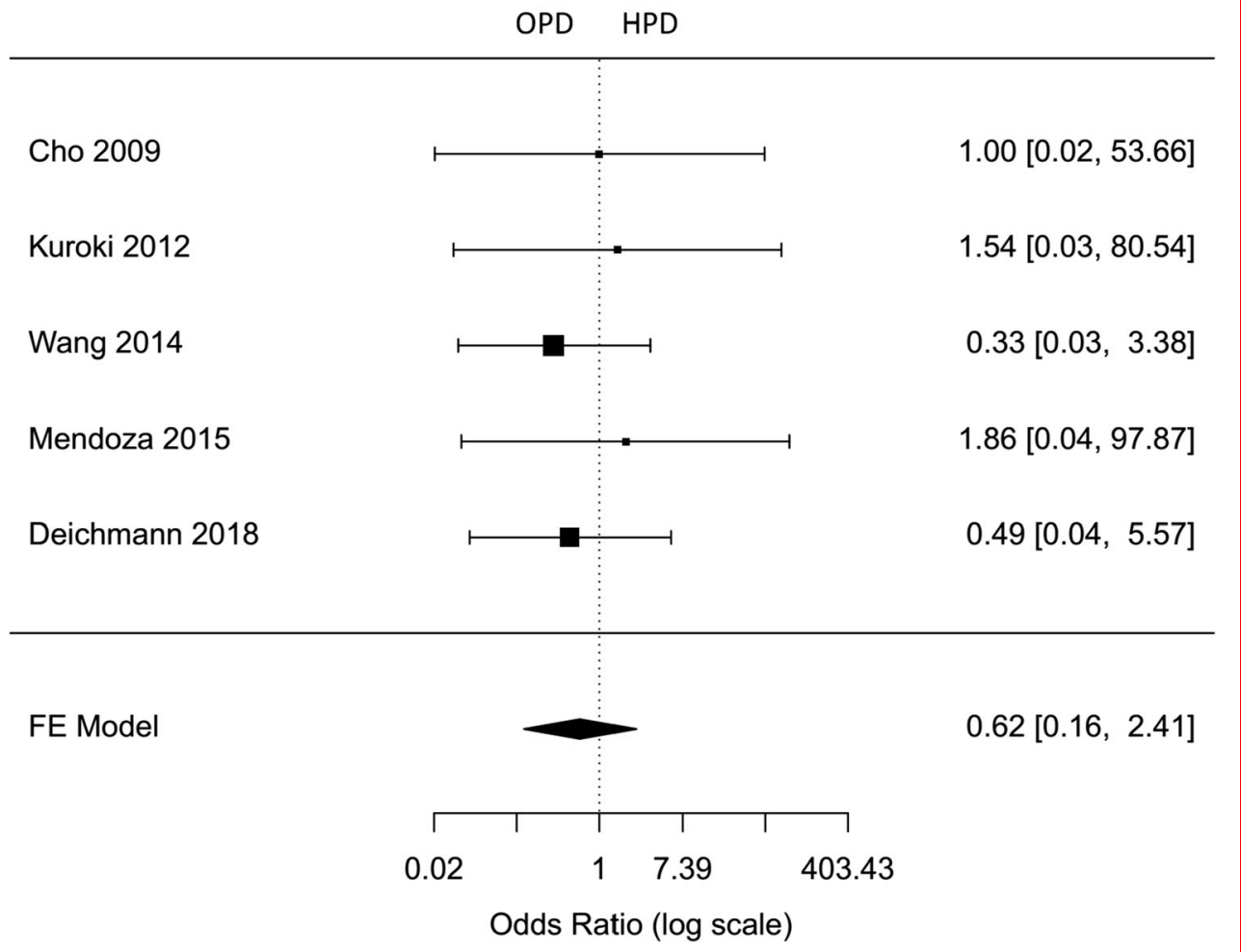

demonstrated the hybrid technique as a safe procedure in high-volume centers with adequate numbers of operations offering aspects of a safe transition to fully laparoscopic/ robotic pancreatoduodenectomy.

Supplementary Information The online version contains supplementary material available at https://doi.org/10.1007/s00268021-06372-1.

Open Access This article is licensed under a Creative Commons Attribution 4.0 International License, which permits use, sharing, adaptation, distribution and reproduction in any medium or format, as long as you give appropriate credit to the original author(s) and the source, provide a link to the Creative Commons licence, and indicate if changes were made. The images or other third party material in this article are included in the article's Creative Commons licence, unless indicated otherwise in a credit line to the material. If material is not included in the article's Creative Commons licence and your intended use is not permitted by statutory regulation or exceeds the permitted use, you will need to obtain permission directly from the copyright holder. To view a copy of this licence, visit http://creativecommons. org/licenses/by/4.0/.

Funding Open Access funding enabled and organized by Projekt DEAL.

\section{References}

1. Dokmak S, Ftériche FS, Aussilhou B et al (2015) Laparoscopic pancreaticoduodenectomy should not be routine for resection of periampullary tumors. J Am Coll Surg 220(5):831-838

2. Kendrick ML, Cusati D et al (2010) Total laparoscopic pancreaticoduodenectomy feasibility and outcome in an early experience. Arch Surg 145(1):19-23

3. Mariette C, Markar S, Dabakuyo-Yonli TS et al (2019) Healthrelated quality of life following hybrid minimally invasive versus open esophagectomy for patients with esophageal cancer, analysis of a multicenter, open-label, randomized phase III controlled trial the MIRO. Ann Surg 271:1023

4. Bausch D, Keck T (2017) Laparoskopische pankreasresektion. Chirurg 88:484-489

5. Keck T, Wellner U, Küsters S et al (2011) Laparoscopic resection of the pancreatic head. Feasib Perioper Results Chirurg 82:691-697

6. Keck T, Kuesters S, Wellner U et al (2011) Laparoscopic pylorus-preserving pancreatic head resection and hybrid open reconstruction via pancreatogastrostomy. J Gastrointest Surg 15:373-377

7. Moher D, Shamseer L, Clarke M et al (2015) Preferred reporting items for systematic review and meta-analysis protocols (PRISMA-P) 2015 statement. Syst Rev 4:1-9

8. Correa-Gallego C, Dinkelspiel HE, Sulimanoff I et al (2014) Minimallyinvasive vs open pancreaticoduodenectomy: systematic review and metaanalysis. J Am Coll Surg 218:129-139

9. De Rooij T, Lu MZ, Steen MW et al (2016) Minimally invasive versus open pancreatoduodenectomy. Systematic review and meta-analysis of comparative cohort and registry studies. Ann Surg 264:257-267 
10. Qin H, Qiu J, Zhao Y et al (2014) Does minimally- invasive pancreaticoduodenectomy have advantages over its open method? A meta-analysis of retrospective studies. PLoS One 9:e104274

11. Zhang H, Wu X, Zhu F et al (2016) Systematic review and metaanalysis of minimally invasive versus open approach for pancreaticoduodenectomy. Surg Endosc 30:5173-5184

12. Higgins JPT, Green S (2011) Cochrane handbook for systematic reviews of interventions version 5.1.0. The Cochrane Collaboration

13. Bassi C, Dervenis C, Butturini G et al (2005) Postoperative pancreatic fistula: an international study group (ISGPF) definition. Surgery 138:8-13

14. Wente MN, Veit JA, Bassi C et al (2007) Postpancreatectomy hemorrhage (PPH): an international study group of pancreatic surgery (ISGPS) definition. Surgery 142:20-25

15. Wente MN, Bassi C, Dervenis C et al (2007) Delayed gastric emptying (DGE) after pancreatic surgery: a suggested definition by the international study group of pancreatic surgery (ISGPS). Surgery 142:761-768

16. Dindo D, Demartines N, Clavien PA (2004) Classification of surgical complications. A new proposal with evaluation in a cohort of 6336 patients and results of a survey. Ann Surg 240:205-213

17. Viechtbauer W (2010) conducting meta-analyses in R with the metafor package. J Stat Softw 36:1-48

18. Higgins JP, Thompson SG (2002) Quantifying heterogeneity in a metaanalysis. Stat Med 21:1539-1558

19. Gagner M, Pomp A (1994) Laparoscopic pylorus-preserving pancreatoduodenectomy. Surg Endosc 8:408-410

20. Cuschieri A (1994) Laparoscopic surgery of the pancreas. J R Coll Surg Edinb 39:178-184

21. Ammori BJ (2004) Laparoscopic hand-assisted pancreaticoduodenectomy: initial UK experience. Surg Endosc 18:717-718

22 Kimura Y, Hirata K, Mukaiya M et al (2005) Hand-assisted laparoscopic pylorus-preserving pancreaticoduodenectomy for pancreas head disease. Am J Surg 189:734-737

23. Staudacher C, Orsenigo E, Baccari P et al (2005) Surg Endosc 19:352-356

24. Mabrut JY, Fernandez-Cruz L, Azagra JS et al (2005) Laparoscopic pancreatic resection: results of a multicenter European study of 127 patients. Surgery 137:597-605

25. Dulucq JL, Wintringer P, Mahajna A (2006) Laparoscopic pancreaticoduodenectomy for benign und malignant diseases. Surg Endosc 20:1045-1050

26. Pugliese R, Scandroglio I, Sansonna F et al (2008) Laparoscopic pancreaticoduodenectomy. A retrospective review of 19 cases. Surg Laparosc Endosc Percutan Tech 18:13-18

27. Cho A, Yamamoto H, Nagata $M$ et al (2009) Comparison of laparoscopyassisted and open pylorus-preserving pancreaticoduodenectomy for periampullary disease. Am J Surg 198:445-449

28. Suzuki O, Kondo S, Hirano S (2012) Laparoscopy pancreaticoduodenectomy combined with minilaparotomy. Surg Today 42:509-513

29. Asbun HJ, Stauffer JA (2012) Laparoscopic vs open pancreaticoduodenectomy: overall outcomes and severity of complications using the accordion severity grading system. J Am Coll Surg 215:810-819

30. Kuroki T, Adachi T, Okamoto T et al (2012) A non-randomized comparative study of laparoscopy-assisted pancreaticoduodenectomy and open pancreaticoduodenectomy. Hepato-Gastroenterology 59:570573

31. Nakamura Y, Matsumoto S, Matsushita A et al (2012) Pancreaticojejunostomy with closure of the pancreatic stupm by endoscopic linear stapler in laparoscopic pancreaticoduodenectomy: a reliable technique and benefits for pancreatic resection. Asian J Endosc Surg 5:191-194

32. Lee JS, Han JH, Na GH et al (2013) Laparoscopic pancreaticoduodenectomy assisted by mini-laparotomy. Surg Laparosc Endosc Percutan Tech 23:e98-102

33. Langan RC, Graham JA, Chin AB et al (2014) Laparoscopicassisted versus open pancreaticoduodenectomy: early favorable physical quality-oflife measures. Surgery 156:379-384

34. Speicher PJ, Nussbaum DP, White RR et al (2014) Defining the learning curve for team-based laparoscopic pancreaticoduodenectomy. Ann Surg Oncol 21:4014-4019

35. Wang Y, Bergman S, Piedimonte S et al (2014) Bridging the gap between open and minimally invasive pancreatiocoduodenectomy: the hybrid approach. Can J Surg 57:263-270

36. Liu Z, Yu MC, Zhao R et al (2015) Laparoscopic pancreaticoduodenectomy via a reverse-"V" approach with four ports: initial experience and perioperative outcomes. World J Gastroenterol 21(5):1588-1594

37. Mendoza AS, Han HS, Yoon YS et al (2015) Laparoscopy-assisted pancreaticoduodenectomy as minimally invasive surgery for periampullary tumors: a comparison of short-term clinical outcomes of laparoscopyassisted pancreaticoduodenectomy and open pancreaticoduodenectomy. J Hepatobiliary Pancreat Sci 22:819-824

38. Zimmitti G, Manzoni A, Addeo P et al (2016) Laparoscopic pancreatoduodenectomy with superior mesenteric artery-first approach and pancreatogastrostomy assisted by mini-laparotomy. Surg Endosc 30:16701671

39. Koh FH, Kow AW (2016) Minimally invasive whipple‘s technique for laparoscopic-assisted pylorus preserving pancreaticoduodenectomy. J Am Coll Surg. https://doi.org/10.1016/j. jamcollsurg.2016.10.052

40. Patel B, Leung U, Lee J et al (2017) Laparoscopic pancreaticoduodenectomy in Brisbane, Australia: an initial experience. ANZ J Surg. https://doi.org/10.1111/ans.14020

41. Van Hilst J, De Rooij T, Van den Boezem P et al (2018) Laparoscopic pancreatoduodenectomy with open or laparoscopic reconstruction during the learning curve: a multicenter propensity score matched study. HPB 21:857-864

42. Deichmann S, Bolm LR, Hoselmann KC et al (2018) Perioperative and long-term oncological results of minimalyy invasive pancreatoduodenectomy as hybrid technique - a matched pair analysis of 120 cases. Zentralbl Chir 143:155-161

43. Pham H, Nahm CB, Hollands M et al (2020) Hybrid laparoscopic pancreatoduodenectomy: an Australian sxperience and a proposed process for impementation. ANZ J Surg. https://doi.org/10. 1111/ans. 15802

44. Wang C, Qi R, Li H et al (2020) Comparison of perioperative and oncological outcomes of hybrid and totally laparoscopic pancreatoduodenectomy. Med Sci Monit 26:e924190

45. Al-Sadairi AR, Mimmo A, Rhaiem R et al (2021) Laparoscopic hybrid pancreaticoduodenectomy: initial single center experience. Ann Hepatobiliary Pancreat Surg 25:102-111

46. Chapman BC, Gajdos C, Hosokawa P et al (2017) Comparison of laparoscopic to open pancreaticoduodenectomy in elderly patients with pancreatic adenocarcinoma. Surg endosc 32:2239

47. Klompmaker S, van Hilst J, Wellner UF et al (2018) Outcomes after minimally-invasive versus open pancreatoduodenectomy a pan-European propensity score matched study for the European consortium on minimally invasive pancreatic surgery (E-MIPS). Ann Surg 20:218

48. Gumbs AA, Rodriguez Rivera AM, Milone L et al (2011) Laparoscopic pancreatoduodenectomy: a review of 285 published cases. Ann Surg Oncol 18:1335-1341 
49. Palanivelu C, Senthilnathan P, Sabnis SC et al (2017) Randomized clinical trial of laparoscopic versus open pancreatoduodenectomy for periampullary tumours. Br J Surg 104:1443-1450

50. Van Hilst J, de Rooij T, Hilal MA et al (2017) Worldwide survey on opinions and use of minimally invasive pancreatic resection. HPB 19:190-204

51. Van Hilst J, de Rooij T, Bosscha K et al (2019) Laparoscopic versus open pancreatoduodenectomy for pancreatic or periampullary tumours (LEOPARD-2): a multicentre, patient-blinded, randomised controlled phase $2 / 3$ trial for the Dutch Pancreatic Cancer Group. Lancet Gastroenterol Hepatol Published Online

52. de Rooij T, van Hilst J, Bosscha K et al (2018) Minimally invasive versus open pancreatoduodenectomy (LEOPARD-2): study protocol for a randomized controlled trial for the Dutch Pancreatic Cancer Group published online

53. de Rooij T, van Hilst J, Boerma D et al (2016) Impact of a nationwide training program in minimally invasive distal pancreatectomy (LAELAPS) for the dutch pancreatic cancer group. Ann Surg 264(5):754-762

54. de Rooij T, van Hilst J, Topal B et al (2017) Outcomes of a multicenter training program in laparoscopic pancreatoduodenectomy (LAELAPS-2) for the dutch pancreatic cancer group. Ann Surg.
55. Adam MA, Choudhury K, Dinan MA et al (2015) Minimally invasive versus open pancreaticoduodenectomy for cancer: practice patterns and short-term outcome among 7061 patients. Ann Surg 262:372-377

56. Sharpe SM, Talamonti MS, Wang CE et al (2015) Early national experience with laparoscopic pancreaticoduodenectomy for ductal adenocarcinoma: a comparison of laparoscopic pancreaticoduodenectomy and open pancreaticoduodenectomy from the nationl cancer database. J Am Coll Surg 221:175-184

57. Wellner UF, Küsters S, Sick O et al (2014) Hybrid laparoscopic versus open pylorus-preserving pancreatoduodenectomy: retrospective matched case comparison in 80 patients. Langenbecks Arch Surg 399:849-856

58. van Hilst J, de Rooij T, van den Boezem PB et al (2019) Laparoscopic pancreatoduodenectomy with open or laparoscopic reconstruction during the learning curve: a multicenter propensity score matched study for the dutch pancreatic cancer group. HPB $21: 857-864$

Publisher's Note Springer Nature remains neutral with regard to jurisdictional claims in published maps and institutional affiliations. 